\section{Acute Transient Pancreatitis Associated With Milk Allergy in an Infant}

Acute pancreatitis is uncommon in children, and is usually due to biliary obstruction, medications, and systemic or idiopathic diseases [1]. Acute pancreatitis associated with food allergy in children is rare, and the mechanism is unclear [2]. We report an infant with acute transient pancreatitis associated with milk (casein) allergy.

A 1-year-old boy presented with a history of urticaria and vomiting after his first exposure to formula milk at the age of 6 months. At that time, his cow milk-specific immunoglobulin $\mathrm{E}$ (IgE) was positive, so milk was avoided. After that, he was continued on a milk-free diet. However, he had eaten meat such as beef, chicken, and pork. On the day of presentation, around 1 hour after eating pork, he vomited and had a rash on his face. His parents gave him an antihistamine preparation and brought him to our hospital. The rash had developed to involve the whole body, but there were no further digestive symptoms or wheezing. He was diagnosed as allergic reaction probably caused by milk, and treated with antihistamines and hydrocortisone, according to the Japanese guideline for food allergy [3]. Later, it was found that the pork contained casein as a meat-softener. As the family had eaten the roasted pork at a restaurant, there was no labeling for casein use as softener. In addition, blood examinations revealed elevations of pancreatic enzymes (total amylase $427 \mathrm{U} / \mathrm{L}$; pancreatic amylase, $423 \mathrm{U} / \mathrm{L}$ (normal, 21-64 $\mathrm{U} / \mathrm{L}$ ); elastase 1, $2480 \mathrm{ng} / \mathrm{dL}$ (normal, $300 \mathrm{ng} / \mathrm{dL}$ ); lipase, $4840 \mathrm{U} /$ $\mathrm{L}$ (normal 17-57 U/L); and phospholipase $\mathrm{A}_{2}, 5390 \mathrm{ng} / \mathrm{dL}$ (normal, 130-400 ng/dL)). Venous base excess was -4.2 , and inflammatory markers and other hepatobiliary enzymes were normal. With a diagnosis of acute pancreatitis, he was treated with fasting, an antibiotic (piperacillin), and a histamine-2 blocker (famotidine). Twelve hours later, the serum pancreatic amylase decreased to $75 \mathrm{U} / \mathrm{L}$, and the urticaria improved. Ultrasonography and computed tomography of the abdomen did not show pancreatic swelling or dilatation of the pancreatic duct. There were no abnormalities of the liver and gastrointestinal tract, and gallbladder. Trial of oral feeds did not lead to abdominal symptoms. At 36 hours after the ingestion, the serum pancreatic amylase level was normalized $(9 \mathrm{U} / \mathrm{L})$, and he was discharged. After one month, all pancreatic enzymes were normal. He was able to eat meat such as beef, chicken, and pork after this event.

Food allergy commonly cause digestive symptoms such as abdominal pain and vomiting associated with food allergy [3]. Pancreatitis associated with food allergy has been widely reported in adults though less common in children [2,4-6]. The prognosis and mechanism are unclear. Previous reports reported no association with sex, type of food that caused the allergy, and the severity of food allergy. However, these reported cases are characterized by having gastrointestinal symptoms (abdominal pain and/or vomiting), absence of abnormalities of hepatobiliary enzymes other than pancreatic enzymes, and a good clinical course. The disorder of the pancreas is expected to be transient. Our case of acute transient pancreatitis associated with milk (casein) allergy also had these characteristics.

Several cases of pancreatitis with food allergen-induced eosinophilic gastroenteritis have been reported. The causes of pancreatitis were assumed to be pancreatic eosinophilic inflammation and local duodenal inflammation [4]. In foodinduced allergic responses, mast cells are involved in digestive symptoms via IgE. Mast cells also have important roles in acute and chronic pancreatitis and multiple organ failure. In the present case, no endoscopic examination was done, so it was not possible to confirm the presence of inflammatory cells in the digestive tract and subsequent pancreatitis. Inamura, et al. [6] proposed that edematous swelling at the ampulla of Vater, associated with mast cell inflammation, caused occlusion of the pancreatic duct and stagnation of pancreatic juice, resulting in pancreatitis. This hypothesis implies that the pancreatitis is a secondary disease following gastrointestinal changes due to allergy. Considering the rapid improvement of pancreatic enzyme levels and the good prognosis, this is the most likely theory.

In conclusion, the present case appeared to have symptoms of milk (casein) allergy, and acute pancreatitis was diagnosed based on biochemical abnormalities. It is necessary to take transient pancreatitis into account as a diagnosis when a child with food allergy shows digestive symptoms.

\section{Yukiko Inada, TakuJi Nakamura and Masafumi Zaitsu* Department of Pediatrics, \\ National Hospital Organization - Ureshino Medical Center, 4279-3 Shimojuku kou, Ureshino, Ureshino City, Saga 843-0393, Japan. *zaitsum@aol.com \\ REFERENCES}

1. Pohl JF, Uc A. Pediatric pancreatitis. Curr Opin Gastroenterol. 2015;31:380-6.

2. Nagakura KI, Yanagida N, Sato S, Ogura K, Ebisawa M. Acquisition of tolerance to egg allergy in a child with repeated egg-induced acute pancreatitis. Allergol Int 2018; 67:535-7.

3. Ebisawa M, Ito K, Fujisawa T; Committee for Japanese Pediatric Guideline for Food Allergy, the Japanese Society of Pediatric Allergy and Clinical Immunology, the Japanese Society of Allergology. Japanese Guidelines for Food Allergy, 2017. Allergol Int. 2017; 66:248-64.

4. Manohar M, Verma AK, Upparahalli Venkateshaiah S, Goyal H, Mishra A. Food-induced acute pancreatitis. Dig Dis Sci. 2017;62:3287-97.

5. Ogura K, Iikura K, Yanagida N, Sato S, Ebisawa M. Two patients with acute pancreatitis after undergoing oral food challenges. J Allergy Clin Immunol Pract. 2016;4:984-6.

6. Inamura H, Kashiwase Y, Morioka J, Kurosawa M. Acute pancreatitis possibly caused by allergy to bananas. J Investig Allergol Clin Immunol. 2005;15:222-4. 